\title{
La aleatoriedad de la condición de víctimas y/o victimarios de la infancia y adolescencia en el conflicto armado colombiano*
}

\author{
The randomness in the condition of victims and / or perpetrators of childhood and \\ adolescence in the Colombian armed conflict \\ Juliana Salomé Díaz Pantoja ${ }^{1} \underline{\operatorname{ORCID}}$
}

Fecha correspondencia:

Recibido: 3 de septiembre de 2019. Revisión: 30 de septiembre de 2019. Aceptado: 5 de octubre de 2019.

Forma de citar:

Díaz, Juliana Salomé. La

aleatoriedad de la condición de

víctimas y/o victimarios de la

infancia y adolescencia en el

conflicto armado colombiano.

Revista CES Derecho. Vol. 10, №. 2 ,

julio - diciembre de 2019, 566-590.

Open access

Términos de uso

Licencia creative commons

Etica de publicaciones

Revisión por pares

Gestión por Open Journal System

DOl: http://dx.doi.org/10.21615/

cesder.10.2.2

ISSN: 2145-7719

Sobre el artículo:

*Artículo de Investigación.

Sobre los autores:

1. Abogada Universidad de Nariño (Col), Magíster en Derecho mención Derecho Familia de la Universidad de Talca (CL.). Doctoranda en Derecho de la Universidad de Talca (CL.). Coordinadora académica Centro de Estudios sobre los Derechos de

\section{Resumen}

La calidad dual víctima-victimario que se le ha atribuido a la infancia y adolescencia vinculada al conflicto armado colombiano, se edifica sobre la falacia de la aleatoriedad, en la que criterios como la edad y la magnitud del delito cometido, se han erigido como elementos fundamentales en la política criminológica del Estado colombiano, factores que consideramos, dada las especificidades en la que se presenta el reclutamiento, como ajenos a su esfera volitiva.

En tal sentido, es preciso plantearnos si la atribución de responsabilidad de tipo punitivo es acorde a los principios de interés superior del niño y capacidad progresiva, o si por el contrario ello implicaría una victimización secundaria devenida desde la institucionalidad, generando la necesidad de contar con un sistema que si bien procure salvaguardar al máximo posible los derechos a la verdad, justicia y reparación de los terceros víctimas, satisfaga los derechos de los niños, niñas y adolescentes vinculados al conflicto armado colombiano.

Palabras clave: Infancia y adolescencia vinculada a conflicto armado, interés superior del niño, autonomía progresiva.

\section{Abstract}

The dual victim-victimizer quality that has been attributed to adolescence linked to the Colombian armed conflict, is built on the fallacy of randomness, in which criterias such as the age and the crimes magnitude committed are fundamental in the criminological politics of the Colombian State, factors that we consider, given the specificities in which the recruitment is presented, as external to its volitional spectra.

In this sense, it is necessary to ask ourselves whether the attribution of a punitive type of responsibility is in accordance with the principles of the best interests of the child and progressive capacity, or if this would imply a secondary victimization from the institutional framework, generating the need to have a system that although seeks to safeguard as much as possible the rights to the truth, justice and reparation of third victims, also satisfies the rights of children and adolescents linked to the Colombian armed conflict. 
la Infancia y Adolescencia -CEDIA- Universidad de Talca (CL.). CONICYT-PFCHAl Doctorado Nacional/201921190350.
Keywords: Childhood and adolescence linked to the Colombian's armed conflict, best interests of the child, Progressive ability

\section{Introducción}

En el mundo, Colombia es el país que por más años ha mantenido un conflicto armado interno, que si bien en muchos periodos gubernamentales no fue reconocido, en la actualidad es posible afirmar que este se originó incluso antes de la creación de las primeras guerrillas liberales en los años $50^{\prime} \mathrm{s}^{1}$. Es de esta manera, que en no menos de 60 años el conflicto ha impactado directamente en los individuos de la sociedad colombiana, siendo la población infantil y adolescente una de las más afectadas por la dinámica de la guerra.

Este trabajo tiene como objetivo el abordar como el citado conflicto social y armado vivido en Colombia ha generado la vulneración sistemática de los derechos de los niños, niñas y adolescentes -NNA- residentes en Colombia en general, y muy particularmente a aquellos afectados por el flagelo del reclutamiento forzado, en su calidad dual de víctimas, pero también -en la mayoría de los casos-como sujetos activos de delitos cometidos en el transcurso de su afiliación a grupos situados al margen de la ley. La respuesta oficial del Estado ante la realidad esgrimida ut supra se basa en un enfoque bifronte: uno "sancionatorio", en tanto posibilita la responsabilidad penal del adolescente excombatiente, y otro "proteccionista", en tanto reconoce que en su calidad de víctima del conflicto armado debe generarse el restablecimiento de sus derechos mediante un proceso administrativo.

Es en este panorama que la presente investigación presenta como hipótesis que amparados en los principios del interés superior del niño/a y de la capacidad progresiva de ejercicio de los derechos, contenidos ambos en la Convención sobre los Derechos del Niño, la intervención sancionatoria no resulta, bajo nuestro punto de vista, una alternativa posible -mucho menos cuando se trata de procesos de justicia transicional- para la satisfacción y restablecimiento de los derechos de la infancia y la adolescencia. Por el contrario, lo que pretende este artículo es demostrar la necesidad de un sistema único de protección que omite por convicción la acción sancionatoria favoreciendo la existencia de un proceso - no penal- capaz de satisfacer los derechos de las víctimas del conflicto como también de los actores armados menores de edad.

La metodología empleada es el método dogmático es el de enjuiciamiento del hecho y analítico serán analizadas tanto las cuestiones fácticas (de facto) como de derecho (de jure) que circunscriben la problemática abordada (Corral, 2008, p. 58) que en nuestro estudio no es otra que la ambivalente regulación de la responsabilidad penal adolescente -visión sancionatoria- y el procedimiento de restablecimiento de los derechos de los NNA combatientes -visión garantista-. La técnica de investigación empleada es la documental, consistente en la recopilación y análisis de fuentes primarias y secundarias -documentos doctrinarios, legislativos, jurisprudenciales y registro de discusiones y episódicos.

Para alcanzar el resultado propuesto hemos dividido el presente estudio en cuatro apartados bien diferenciados entre sí. El primero de ellos, presenta las especificidades propias del reclutamiento forzado en el contexto del conflicto armado colombiano,

1. No obstante lo anterior, la fecha de los orígenes del conflicto armado colombiano evoca múltiples discrepancias en la doctrina, destacándose por un lado aquellos que apoyan una mirada del conflicto desde el pasado más remoto considerando incluso las particularidades de la formación del Estado-Nación colombiano a fin de esclarecer los factores de incidencia en los periodos de violencia (Vega, 2016, p. 1 y ss; Wills, 2016, p. 1 y ss), mientras que desde otra mirada -históricamente más restringida- encontramos quienes a pesar de reconocer la importancia histórica en el conflicto armado colombiano afirman que el mismo puede desentrañarse en un periodo más limitado como el evidenciado con posterioridad al Frente Nacional. (Gutiérrez, 2016, p. 1 y ss: Duncan 2016; Giraldo, 2016. p. 1 y ss). 
evidenciando la calidad dual de víctimas y victimarios de los NNA combatientes. Acto seguido, el punto segundo, nos detalla los diferentes lineamientos internacionales y nacionales de protección aplicables a los NNA involucrados en los conflictos armados. En tercer término, y centrándonos ahora en los intentos de dar salida al denominado "conflicto colombiano", se aborda el tratamiento de la responsabilidad generado a partir de los dos últimos procesos de justicia transicional vivenciados en Colombia. Finalmente, en el último acápite formulamos, bajo los parámetros de los principios transversales del interés superior del niño/a y capacidad progresiva de ejercicio de derechos, un nuevo instrumento teórico de responsabilidad que permita vislumbrar los grados de culpabilidad admisibles en contextos de justicia transicional para NNA combatientes.

\section{Particularidades del reclutamiento forzado de las niños, niñas y adolescentes en el conflicto armado colombiano}

Colombia ha atravesado a lo largo de su historia diversos conflictos armados, siendo el vivido desde la mitad del siglo XX hasta la actualidad, no solo el más largo del país, sino también el conflicto armado interno con mayor duración a nivel internacional. Es por ello que la violencia ha sido un componente trasversal en todo el desarrollo legal e institucional colombiano (Fals, Guzmán Y Umaña, 2005, p. 32), convirtiéndose en la base principal de la cotidianidad social y por ende un factor de desenvolvimiento económico, político y cultural (Rojas, 1993, p. 55-56; Torres 1963, p. 1 y ss).

En este sentido es posible identificar al panorama colombiano como un conflicto de raigambre social y política, de larga duración, de baja intensidad y con una pluralidad de actores armados involucrados, en el cual se ha generado una vulneración sistemática de derechos tanto a los individuos como a las organizaciones familiares conformadas a lo largo de todo el territorio del país, no siendo posible desconocer la existencia de un impacto diferenciado en los diversos sectores de la población. Efectivamente, los niveles de victimización de la ciudadanía no siempre obedecen a una ratio paritaria, por lo que los efectos del conflicto no son los mismos, por ejemplo, entre los habitantes propios de zonas rurales y urbanas, como tampoco lo son si se toma en consideración la perspectiva de género (ataques sexuales) o se atiende a ciertas comunidades indígenas o afrodescendientes (asesinato selectivo), e idéntica circunstancia se suscita al referirse al factor etario (reclutamiento forzado).

Llegados a este punto, y a efectos de hacer un análisis del impacto del conflicto armado con un enfoque diferencial etario, a continuación se desarrollará un breve acercamiento a la dinámica propia del reclutamiento forzado de los NNA en el conflicto armado colombiano, para posteriormente evidenciar la calidad dual de víctimas y victimarios de la infancia y adolescencia excombatiente.

\section{De la voluntad de los niños, niñas y adolescentes frente a su ingreso en los grupos insurgentes}

Consideramos que las principales motivaciones de la población infantil y adolescente para incorporarse a los grupos armados son: la carencia de posibilidades de educación y de sostenimiento; el desgarro social causado por la guerra; los lazos de parentesco y amistad con miembros de grupos armados; la necesidad de protección de otros grupos armados por la intimidación, secuestro o abducción; y la necesidad de escapar de contextos de abuso y violencia doméstica (Hernandez, 2001, p. 3; Human Rights Watch, 2003, p. 23 y ss). 
La mayoría de la población infantil y adolescente -aproximadamente un 81\%- manifiesta haberse incorporado a los grupos insurgentes de manera aparentemente "voluntaria" (Springer, 2012, p. 30; Defensoría del Pueblo, 2006, p. 7: Human Rights Watch, 2003, p. 9). No obstante, se evidencia que la libertad de ingresar a los grupos armados se encuentra considerablemente condicionada por las circunstancias de extrema marginalidad y desigualdades sociales, carencias y precaria presencia y asistencia estatal vivenciadas por esta población que les deja como única opción el ingreso a los grupos armados.

Dado el contexto de violencia del conflicto armado en Colombia y las condiciones de vulnerabilidad social y económica en las que se encuentran los NNA al momento del reclutamiento, una parte importante de la doctrina ${ }^{2}$ así como la Defensoría del Pueblo (2014) y la Corte Constitucional de Colombia - a través de Sentencia C-240 de 2009 y Auto 251 de 2008- entienden que en ningún caso en su vinculación al grupo armado media su voluntad, ello por cuanto el contexto violento en el que se produce elimina cualquier consideración de voluntariedad. Los NNA combatientes son retenidas y obligadas a convertirse en victimarios, sin tener por ende derecho a abandonar las filas ni a expresar sus opiniones (Springer, 2012, p. 31),

\section{Calidad dual -víctimas y victimarios- de la infancia y adoles- cencia combatiente}

De lo apuntado ut supra, es posible evidenciar que una de las problemáticas más visibilizadas ${ }^{3}$ respecto a la población infantil y adolescente es el reclutamiento forzado de los NNA "vinculados a la guerra como expresión de la tendencia creciente de los actores armados a utilizar a la población civil como táctica de guerra y de la degradación del conflicto armado producto de su prolongación"( Hernández, 2001, p. 4). Según el informe del Centro Nacional de Memoria Histórica (2012) "Basta Ya", entre 1999 y 2012, fueron registrados 6.156 NNA como víctimas de reclutamiento forzado, sin embargo, el estimativo sobre el número de NNA combatientes en Colombia carece de certeza y fluctúa ampliamente dependiendo de la organización gubernamental o no gubernamental que realiza el informe 4 .

Precisado lo anterior, no podemos olvidar que Los NNA en el desarrollo del conflicto además de ser sujetos pasivos del delito de reclutamiento forzado, adquieren la calidad de sujetos activos de delitos como combatientes directos, o también como guardias, mensajeros e informantes, por lo que de manera conclusiva Springer (2012) precisa que "se trata de una práctica que compromete múltiples violaciones graves a los derechos humanos, ejecutada de manera sistemática y consumada con la clara intención de someter a una población especialmente vulnerable. De convertir a las víctimas en victimarios" (p. 40). Es en este contexto que críticamente se abre la puerta para la judicialización de los menores combatientes por la responsabilidad de las acciones cometidos durante su permanencia en las filas de los grupos ilegales, ello de conformidad con los lineamientos internacionales

2. En necesario anotar, como lo hace Bacares (2015), que "detrás de la existencia de las infancias enroladas en los mandatos castrenses, se oculta una relación delictual que trasluce a dos personajes opuestos: por un lado, alguien que ejecuta, planea y permite la incorporación de los NNA -niños, niñas y adolescentes- a las funciones obligatorias de las hostilidades, y por otro, un sujeto pasivo de la infracción penal, a quien se le violan en lo sucesivo sus derechos fundamentales" (p. 248).

3. A menudo se presenta una invisibilización de otras formas de impacto del conflicto armado hacia los niños, niñas y adolescentes expuestos a ser víctimas de amenazas, masacres, homicidios, desapariciones, torturas, ataques indiscriminados, accidentes por minas antipersonal, enfrentamientos armados, desplazamientos forzados entre otras acciones calificadas como infracciones al derecho internacional humanitario, e inclusive como crímenes de guerra. (Defensoría del Pueblo, 2006, p. 6); (Consejo de Seguridad de las Naciones Unidas, 2016, p. 10 y ss).

4. Así por ejemplo cifras aportados por Human Rights Watch estimaban que el número total de niños/as combatientes en Colombia ascendía a 11.000. Por su parte la Fiscalía General de la Nación a través de la Dirección y Análisis de Contexto estima una cifra de 11.556 personas menores reclutadas entre 1975 hasta el año 2014, solo por parte de las FARC-EP. Paralelamente el ICBF ha atendido a 4.323 niños y niñas durante el período del 16 de noviembre de 1999 al 31 de mayo de 2010. (Human Rights Watch, 2003, p. 6; Dirección Nacional de Análisis y Contextos -DINAC, 2016; Consejo Nacional de Política Económica y Social República de Colombia, 2010, p. 55). 
contentivos de estándares mínimos que reflejan las reglas y garantías reconocidas en la tramitación de los procesos de juzgamiento adelantados contra NNA.

Así, frente al tratamiento de la infancia y la adolescencia desde su triple condición de (1) personas menores de edad sujetas a especial protección, (2) víctimas del delito de reclutamiento forzado, y (3) personas infractoras de la ley penal, debemos dilucidar la forma en cómo estos menores se enfrentan ante los derechos de las víctimas a la verdad, a la justicia y a la reparación mediante un proceso de responsabilidad penal adolescente (Rojas, (2016), p. 1 y ss.; Patiño, (2015), p. 7 y ss.; Villalva, (2012), p. 66 y ss.; Corte Constitucional de Colombia Sentencia C-203/05).

En tal medida, resulta clara la disyuntiva entre la intervención sancionatoria que implica una cierta limitación de la libertad del menor combatiente, y el intento de restablecimiento de los derechos de la infancia y la adolescencia amenazados o violados por el contexto del conflicto armado y que en principio, no puede implicar restricción de sus derechos, sino, por el contrario, la garantía y restablecimiento de los mismos (Couso, 1999, p. 83).

\section{Lineamientos de protección a los niños, niñas y adolescentes involucrados en conflictos armados}

Apuntados los principales rasgos del conflicto armado colombiano y detallada la dinámica generada hacia la población infantil y adolescente víctima del reclutamiento forzado, a continuación se esboza la normativa aplicable a la infancia y la adolescencia involucrada en conflictos armados. En primera instancia, serán analizados los lineamientos internacionales y nacionales generados en torno a los NNA en su calidad de sujetos de especial protección. Para ello, se analizará el cambio paradigmático devenido a partir de la Convención sobre los Derechos del Niño/a en el tratamiento de la infancia y adolescencia. Seguidamente, se formulará una mención acerca de la normativa consolidada hacia la población infantil y adolescente en su condición de víctimas del delito de reclutamiento forzado, para finalmente enfrentarnos a las regulaciones generadas alrededor de la población infantil y adolescente en contextos de infracción de la ley penal.

\section{Individuos menores de edad como sujetos dignos de especial protección}

La Convención sobre los Derechos del Niño (en adelante CDN) de 20 de noviembre de $1989^{5}$, generó un punto de inflexión en el tratamiento de la infancia puesto que además de brindar mayor precisión a los derechos incorporados en instrumentos precedentes, se propició el cambio de la doctrina de la "situación irregular" hacia la doctrina de la "protección integral" en la que el niño deja de ser tratado como un objeto pasivo del derecho para abrir paso a la idea del niño como sujeto titular de derechos (Castro y Hernández, 2010, p. 65)․ De esta manera y como lo preceptúa Solari (2016), "mientras que en el viejo régimen se trata de satisfacer necesidades, en el nuevo -modelo- esas necesidades se transforman en derechos. Antes -la persona menor de edad- tenia necesidades de alimentación, educación y salud; ahora tiene derecho a la alimentación, salud y educación" (p. 8).

5. Colombia ratificó la CDN por medio de Ley 12 de 22 de enero de 1991

6. Esta concepción es fruto como precisa FANLO (2004) "del progresivo descubrimiento social y cultural de la niñez y la adolescencia como fases específicas de la existencia humana merecedoras de una especial atención -y derechos" (p. 8.) En igual sentido CILlero (2013) planetaria que "ser niño no es ser "menos adulto", la niñez no es una etapa de preparación para la vida adulta. La infancia y la adolescencia son formas de ser persona y tienen igual valor que cualquier otra etapa de la vida Tampoco la infancia es coneptulizada como una fase de la vida definida a partir de las ideas de dependencia o subordinación a los padresu otros adultos. La infancia es concebida como una época de desarrollo la vectivoy progresivo de la autonomía personat, socia y jurídica". (p. 4) 
Es precisamente una de las principales virtudes de la CDN la de equiparar la titularidad de derechos en la infancia y en la adultez, lo cual, se reitera, implica otorgar a la infancia la calidad de sujetos de derechos humanos y civiles, con algunas prevenciones especiales referidas al ejercicio de sus derechos, en función de su edad y madurez y de la salvaguarda de los derechos de sus progenitores y cuidadores (Correa y Vargas, 2011, p. 179). En concordancia con el establecimiento de este modelo reivindicativo sobre la dignidad de la infancia, la CDN enfatizó la especial protección de la que goza esta población atendiendo al interés superior del niño/a (art. 3-1), así como también en el reconocimiento del papel del Estado como garante de las medidas de protección y cuidado necesarios para el efectivo acceso y disfrute de todos los derechos de los NNA (art. 3-2).

En el contexto interno, además de las disposiciones previamente señaladas y que son aplicables en virtud de lo dispuesto en los artículos 93 y 94 de la Constitución Política que establecen la integración de los tratados y convenios internacionales en el ordenamiento interno mediante el Bloque de Constitucionalidad, esta protección especial de la que gozan los NNA -calidad que en Colombia se ostenta hasta los 18 años- está amparada constitucionalmente a través de los artículos 44 y 45, así como también por las disposiciones contempladas en el Código de la infancia y la adolescencia especialmente en sus art. 8 y 9 que establecen el interés superior de los niños/as y la prevalencia de sus derechos respectivamente.

\section{Normativa aplicable a los niños, niñas y adolescentes como víctimas del delito de reclutamiento forzado}

Además de la calidad de sujetos de especial protección por su condición de personas menores de edad, los NNA combatientes en tanto víctimas de delito de reclutamiento forzado son sujetos de protección reforzada por parte del Derecho Internacional Humanitario y el Derecho Internacional de los Derechos Humanos, como se ha plasmado en una gran variedad de instrumentos internacionales, tales como el Convenio IV de Ginebra de 1949 que junto a los dos Protocolos Adicionales a los Convenios de Ginebra, establecieron la prohibición de la participación -directa o indirecta- de las personas menores de 15 años en las hostilidades. Por su parte el Estatuto de Roma tipificó el reclutamiento, alistamiento o utilización en hostilidades de individuos menores de 15 años como un crimen de guerra (art. 8). Seguidamente, la CDN (art. 38) impuso a los Estados partes la obligación de adoptar medidas para garantizar la protección de la infancia y adolescencia a fin de evitar su participación directa en los conflictos armados, o su reclutamiento forzado por parte de los grupos insurgentes. Igualmente, el Convenio 182 de la OIT de 1999 mediante el cual los Estados se obligan a adoptar las medidas inmediatas y eficaces para conseguir la prohibición y la eliminación de las peores formas de trabajo infantil, hace mención expresa al reclutamiento forzoso u obligatorio de NNA para utilizarlos en conflictos armados (arts. 1 y 3, literal a). Más adelante en la misma tendencia, se aprobó el Protocolo Facultativo de la CDN de 2000, por medio del cual se impuso a los Estados Partes la implementación de medidas a fin de evitar el reclutamiento o utilización en hostilidades a menores de 18 años (arts. 3 y 4) ${ }^{8}$.

7. Aun cuando inicialmente el art. 38 de la CDN había establecido los 15 años como la edad mínima para permitir cualquier participación de los individuos menores en hostilidades y reclutamiento por parte de los distintos grupos armados, Colombia formuló reservas a los numerales segundo y tercero de mentado artículo estableciendo como edad mínima para el reclutamiento militar los 18 años de edad.

8. Colombia aprobó el protocolo mediante la Ley No 833 de 2003, siendo depositado el 25 de mayo de 2005 ante la Secretaría General de las Naciones Unidas el instrumento de ratificación, para posteriormente ser promulgado mediante Decreto № 3966 de 8 de noviembre de 2005 del Ministerio de Relaciones Exteriores. El Estado colombiano presentó el informe inicial del protocolo el 24 de septiembre de 2008 -aunque debía presentarse en 2007 - Comité de los Derechos del Niño/a (2010), párr. 1 y ss. El Comité de Derechos del Niño realizó el examen del informe 25 de mayo a 11 de junio de 2010 , instando al Estado Colombiano a la adopción de todas las medidas posibles para eliminar las causas fundamentales del reclutamiento por grupos armados que no sean las fuerzas armadas del Estado, así como el brindar un adecuado tratamiento de los niños/as que hayan sido reclutados. Comité de los Derechos del Niño/a (2010), párr. 27 a-b. Posteriormente, en las Observaciones finales sobre los informes periódicos cuarto y quinto combinados de Colombia, si bien el Comité de Derechos del Niño/a reconoce los esfuerzos realizados por el Estado Colombiano en materia de prevención de reclutamiento forzado tales como la creación del Sistema de Alerta Tempranas y la Comisión intersectorial para la prevención del reclutamiento le insta a que amplíe les brinde una financiación estatal más amplia y regular así como un mayor nivel de coordinación entre las distintas entidades estatales que se encargan de la prevención 
En el plano interno colombiano, el reclutamiento de NNA se encuentra tipificado como delito por el art. 162 del Código penal (Ley 599 de 2000), mientras que su calidad de víctimas se encuentra reconocida expresamente mediante ley 1448 de $2011^{9}$ (art. 3 y 190). Paralelamente y bajo un prisma más prevencionista encontramos diversas normativas que establecen los lineamientos para la protección y prevención de este flagelo, destacándose entre otras, el Código de Infancia y Adolescencia que expresamente atribuye al Estado Colombiano la obligación de proteger a la población infantil y adolescente contra su vinculación y reclutamiento por parte de grupos al margen de la ley (numeral 7 del art. 20 y numeral 30 del art. 41), así como el Decreto 4690 de 2007 mediante el cual se crea la "Comisión Intersectorial para la prevención del reclutamiento y utilización de NNA por grupos organizados al margen de la ley" en la que se agrupa a una serie de entidades para trabajar en la prevención de este fenómeno y más adelante se expide el documento del Consejo Nacional de Política Económica y Social -CONPES- 3673 (2010) mediante el cual se desarrolla una "política de prevención del reclutamiento y utilización de NNA por parte de los grupos armados organizados al margen de la ley y de los grupos delictivos organizados" (p. 1) 10

\section{Normativa aplicable a los niños, niñas y adolescentes como infractores de ley penal}

Paralelamente al reconocimiento de la población infantil y adolescente como individuos en pleno proceso de desarrollo y consecuentemente merecedores de una especial protección jurídica de sus derechos, se ha forjado desde el contexto internacional una tendencia que frente a la responsabilidad penal adolescente avoca por limitar el papel del ius puniendi a través del máximo respeto a los derechos del sujeto menor de edad, siguiendo una política criminal concreta que persiga no solo la reparación del daño sino también la rehabilitación y reinserción social del sujeto menor de edad.

Al efecto es posible advertir el surgimiento de una amplia gama de lineamientos internacionales, tales como el artículo 19 de la Convención Americana, el artículo VII de la Declaración Americana, la CDN, las Reglas Mínimas de las Naciones Unidas para la administración de la justicia de menores, conocidas como "Reglas de Beijing" de 1985, las Reglas Mínimas de las Naciones Unidas sobre las Medidas No Privativas de la Libertad de 1990 ("Reglas de Tokio"), las Reglas para la protección de menores privados de la libertad de 1990 ("Reglas de La Habana") y las Directrices de las Naciones Unidas para la Prevención de la Delincuencia Juvenil de 1990 ("Directrices de Riad"), además de los instrumentos internacionales sobre derechos humanos de alcance general, todos ellos contentivos de estándares mínimos que reflejan las reglas y garantías reconocidas en la tramitación de los procesos de juzgamiento adelantados contra NNA.

De manera general los lineamientos antes mencionados, además de reconocer a las NNA todas las garantías que les corresponden a los adultos en los juicios criminales, también les atribuyen una serie de garantías específicas ligadas a su condición de personas en proceso de formación (Belof 1998, p. 91), y que en la práctica tal como lo plantea Duce se reflejan en criterios y estándares que marcan los alcances del derecho a un tratamiento especial y diferenciado en su juzgamiento por infracciones a la ley penal (Duce, 2009, p- 73 y ss: Belof, 1998, p. 91; Capello, 2013, p. 75).

del reclutamiento, a fin de su rol sea efectivo. (Comité de los Derechos del Niño/a, 2015, párrs. 18 y 19.)

9. Si bien es cierto los niños, niñas y adolescentes víctimas del delito de reclutamiento forzado habían sido reconocidos, de una u otra forma, como víctimas por leyes anteriores (ley 418 de 1997 y la ley 782 de 2002), sería a la luz de los paradigmas de la ley 1448 de 2011 que tal posición política y legislativa resultaría unánime y refrendada. (Bacares, 2015, p. 241).

10. Para mayor información véase el informe del Observatorio de Procesos de Desarme, Desmovilización y Reintegración (2011). 
Es preciso reiterar que los lineamientos de configuración del sistema penal adolescente orientan la política criminal hacía la utilización de la pena privativa de la libertad como medida excepcional y de ultima ratio, bajo la lógica planteada por Ferrajoli (1995) en la que:

"la libertad -como la vida- es en realidad un derecho personalísimo, inalienable e indisponible y, por consiguiente conforme al argumento de Beccaria, su privación total debería estar prohibida; mientras que los demás derechos, que son indisponibles, permiten formas bastantemente más variadas y tolerables de privación o delimitación". (p. 420)

En cumplimiento de tales parámetros, el sistema de responsabilidad penal para adolescentes en Colombia -regulado por el Código de infancia y adolescencia- estableció una legislación integral para el juzgamiento de delitos cometidos por personas que tengan entre catorce (14) y dieciocho (18) años al momento de cometer el hecho punible, sistema caracterizado -al menos teóricamente hablando- por su carácter pedagógico, específico y diferenciado con respecto del sistema de adultos y cuya finalidad es la de garantizar la justicia restaurativa, la verdad y la reparación del daño. En el mismo sentido, contempla como último recurso la privación de la libertad y promueve salidas anticipadas para resolver los conflictos generados, así como también insta a la aplicación de manera preferente del principio de oportunidad.

Específicamente frente a las NNA vinculadas al conflicto como combatientes, el ordenamiento jurídico colombiano reconoce que ante la comisión de hechos punibles en el transcurso de su afiliación a las filas de grupos insurgentes, podrán ser sujetos a procesos judiciales destinados a establecer su responsabilidad penal ${ }^{11}$. También es este sentido se pronunció la Corte Constitucional de Colombia mediante sentencia C- 203 de 2005.

En concordancia a lo anterior, el Código de Infancia y adolescencia a través de su art. 175 y atendiendo a la especificidad de la política criminal del sistema de responsabilidad penal de los adolescentes, faculta al ente investigador -Fiscalía General de la Nación- a renunciar a la persecución penal de los adolescentes excombatientes infractores mediante la aplicación del principio de oportunidad. Tal facultad, sin embargo, se elimina cuando se trate de hechos que puedan significar violaciones graves al derecho internacional humanitario, crímenes de lesa humanidad o genocidio.

Una vez analizada los lineamientos nacionales e internacionales de protección a las NNA vinculadas al conflicto armado colombiano, en las siguientes páginas daremos observación del impacto de dichos lineamientos en el tratamiento precisado en los dos últimos procesos de justicia transicional vivenciados en Colombia.

\section{Respuestas de los procesos transicionales colombianos}

En la búsqueda continua de la paz, se han realizado en Colombia varios procesos de negociación política entre el Estado y diversos grupos guerrilleros y paramilitares, sin embargo han sido los procesos de "Justicia y Paz" de 2005 y el Acuerdo de paz del Teatro Colon de 2016 los que -más allá de la discusión sobre la real y efectiva transición y desmovilización- han generado manifestaciones de justicia transicional (Rúa, 2015, p. 85 y ss), mediante la formulación de una serie de cambios estructurales -al menos en el terreno formal y legalista- sobre la justicia, la verdad, la

11. En este sentido el parágrafo 2 del artículo 19 de la Ley 782 de 2002, permite la judicialización de las NNA vinculadas al conflicto armado colombiano, en tanto ordena a la autoridad judicial competente la remisión de documentación al Comité Operativo para la Dejación de las Armas, para que expida la correspondiente calificación sobre la concesión o no de beneficios como el indulto. 
reparación y la memoria en búsqueda de la transformación del modelo institucional, normativo y político que impida la continuidad del conflicto armado a fin de transitar hacia la consolidación de una paz estable y duradera ${ }^{12}$.

Ciertamente, es posible evidenciar como lo plantea Uprimny (2006), que dicha "transformación -ha implicado- la difícil tarea de lograr un equilibrio entre las exigencias de justicia y paz, es decir, entre los derechos de las víctimas del conflicto y las condiciones impuestas por los actores armados para desmovilizarse" (p. 8), superando los polos que representaban la justicia retributiva y la impunidad total (Rúa, 2016, p. 459). Es bajo estas premisas que, acto seguido, se analizará cuál ha sido el tratamiento otorgado a las NNA combatientes que se han sometido a los ya mencionados procesos transicionales.

\section{Justicia y Paz 2005}

La negociación política generada entre el Estado Colombiano y las llamadas Autodefensas Unidas de Colombia (AUC) posibilitó la expedición de la Ley 975 de 2005, conocida como Ley de Justicia y Paz mediante la cual se creó la "Jurisdicción Penal Especial de Justicia y Paz" como un mecanismo de justicia transicional. El marco legal contemplado en la mencionada ley fue modificado tres veces en atención a las decisiones de las Altas Cortes ${ }^{13}$ hasta la adopción de la Ley 1424 de 2010, ello por cuanto no satisfacía los preceptos constitucionales e internacionales en favor a las víctimas del conflicto. Más adelante se introducirían reformas estructurales -en materia de investigación, persecución penal y reparación de víctimas- mediante la Ley 1592 de 2012.

En lo que atañe a los NNA vinculadas a grupos armados, la Ley de Justicia y Paz estableció la obligación a todos los grupos sometidos al proceso de entregar a la autoridad competente -Instituto Colombiano de Bienestar Familiar o ICBF- a los NNA reclutados, so pena de perder los beneficios jurídicos y administrativos que derivan de la desmovilización (numeral 3 del art. 10 y art. 64). Si bien es cierto tal disposición refuerza la calidad de víctimas que la población infantil y adolescente ostenta como consecuencia de los periplos bélicos, en la practica la falta de una política estatal clara en el manejo de menores desvinculados en su condición de víctimas, aunado a la aquiescencia misma de los funcionarios hacia el ocultamiento de la realidad de reclutamiento forzado basadas en políticas de Estado que preferían el rápido transito del proceso transicional, imposibilitó la identificación de los NNA víctimas de reclutamiento, el restablecimiento de sus derechos sistemáticamente vulnerados y el otorgamiento de la protección integral de la que son sujetos titulares (Watch List, 2012, p. 21; Defensoría del Pueblo Colombia, 2014, p. 83).

Al efecto es posible advertir que en el marco de las desmovilizaciones colectivas de estructuras de Autodefensas solo 432 personas menores de 18 años fueron puestas a disposición del ICBF ${ }^{14}$, cantidad considerablemente inferior a la estimada de menores que estaban en sus filas -esto es aproximadamente el $20 \%$ de los 31.617 que se desmovilizaron-. Tal situación, se reitera, es fruto de una política encaminada a reducir el número oficial de menores de edad reportados en sus filas, que de conformidad con las declaraciones brindadas por algunos de los excomandantes de las AUC, respondió a una idea expresada desde la institucionalidad a través del Alto Comisionado para la Paz con el fin de no entorpecer el proceso y no comprometer

12. En una definición similar, entre otros, ver: García Y Giraldo (2016), p. 98; Gómez Y Correa (2015), p. 196; Rush et al. (2014), p. V; Sentencia C-579 de 2013 de Corte Constitucional Colombia.; Lucero (2012), pp. 8-10; Uprimny (2006), p. 8 ,

13. Al respecto véase Sentencia C-370 de 2006 Corte Constitucional y Comisión Colombiana de Juristas (2007). pp. 13 y ss.

14. Correspondiente a las cifras de la Oficina del Alto Comisionado para la Paz acerca de los individuos menores de edad desvinculados atendidos por el ICBF entre noviembre de 1999 y diciembre de 2015. (Observatorio de Paz y Conflicto, 2015). 
su legitimidad a nivel internacional (Observatorio de Procesos de Desarme, Desmovilización y Reintegración, 2010, p. 11 y 12).

A pesar de la situación anterior, es posible afirmar que en el desarrollo de los procesos de justicia transicional de la Ley 975 de 2005, se ha permitido en cierta medida develar el contexto y los hechos del reclutamiento así como la identificación y el establecimiento de la responsabilidad de los sujetos activos del reclutamiento forzado (Defensoría del Pueblo Colombia, 2014, p. 85), lo cual se ha traducido en la promulgación de 13 sentencias condenatorias en contra de 44 ex-miembros de Autodefensas por el delito de 1208 casos de reclutamiento forzado (Observatorio de Paz y Conflicto, 2016, p, 15 y ss).

En cuanto a la responsabilidad penal de los menores de edad desvinculados de los grupos armados, es posible evidenciar una indeterminación jurídica atendiendo a que, no obstante el marco normativo del proceso transicional de Justicia y Paz entiende a la población infantil y adolescente exclusivamente como víctimas del delito de reclutamiento forzado, en la práctica y de conformidad con las disposiciones del ordenamiento jurídico colombiano tal calidad no impide su persecución penal cuando se hayan cometido delitos en el transcurso de su afiliación al grupo armado.

\section{Acuerdo de paz Teatro Colon 2016}

Por su parte los diálogos de paz entre el Estado colombiano y la guerrilla FARC-EP dieron origen al "Acuerdo Final para la Terminación del Conflicto y la Construcción de una Paz Estable y Duradera" mediante el cual se acordó, entre otros, en el punto tercero denominado "Cese al Fuego y de Hostilidades Bilaterales y Definitivas y la Dejación de las Armas" un apartado especial respecto de la reincorporación de los NNA desvinculados, en el que además de reiterar su calidad de víctimas -y derivado de ello los derechos, beneficios y prestaciones establecidas tanto por su condición de víctimas como los derivados de su proceso de reincorporación- se exige la implementación de un programa de reintegración a cargo del Consejo Nacional de Reincorporación guiado bajo los lineamientos establecidos en el Comunicado Conjunto No. 70 de 2016 (Acuerdo final, 2016, p. 75).

Al efecto es posible advertir que, las directrices generadas a partir del mencionado comunicado, instan a la consolidación de una serie de medidas de especial atención y protección enfocadas en el restablecimiento de sus derechos fundamentales, principalmente el derecho a la familia -mediante la priorización de la reintegración familiar y comunitaria-, la salud, la educación, la dignidad, la intimidad, su participación activa, y en general la implementación de medidas guiadas por el principio del interés superior del niño/a (Acuerdo final, 2016, p. 74).

Igualmente, el comunicado Conjunto No. 70 de 2016 establece, entre otros, los compromisos asumidos por parte de las FARC-EP de suministrar la información sobre los sujetos menores de 15 años que serían desvinculados y entregados a la autoridad competente, la de contribuir a la identificación de todos los menores de edad vinculados a la organización y finalmente tomar las medidas para garantizar la salida progresiva de todos los menores de edad que se encuentran en sus campamentos (Gobierno Nacional de Colombia y FARC-EP -comunicado Conjunto No. 70-, 2016, p. 2).

No obstante la importancia del acuerdo mencionado ut supra, el mismo encuentra a nuestro juicio dos limitantes importantes, por un lado en tanto la salida de los sujetos menores de edad se limita a aquellos menores de 15 años, lo que desconoce abiertamente los lineamientos internacionales y nacionales que contemplan los 18 
años como la edad mínima para el ingreso a fuerzas armadas, adicionalmente pese a los compromisos asumidos por parte de las FARC-EP, en la práctica solo 119 NNA fueron entregadas a la autoridad competente. Esta cifra desestima la magnitud del fenómeno del reclutamiento teniendo en cuenta que para el año 2012 aproximadamente cuatro de cada diez combatientes de las FARC eran NNA, constituyendo el $42 \%$ del pie de fuerza en combate (Springer, 2012, p. 30).

Así mismo, el acuerdo permitió la creación de la Jurisdicción Especial para la Paz (JEP) bajo el modelo de justicia transicional que forma parte del componente judicial del Sistema Integral de Verdad, Justicia, Reparación y No Repetición, desarrollado parcialmente mediante Ley 1820 de 2016. En este sentido, la JEP se erige sobre la necesidad de equilibrar los derechos de las víctimas a la verdad, justicia y reparación, con las exigencias de los actores armados participes del proceso de desmovilización. Bajo esta perspectiva, y al margen de los delitos que puedan ser sujetos a indulto o amnistía, se confiere a la JEP el deber de investigar, esclarecer, perseguir, juzgar y sancionar las graves violaciones a los derechos humanos y las graves infracciones al Derecho Internacional Humanitario que acaecieron durante y en razón al conflicto armado.

En lo que atañe a las personas menores de edad entre 14 a 18 años, en términos generales se aplicará el beneficio del indulto por rebelión y delitos conexos, igual como sucede con las personas mayores de edad, sin embargo el tratamiento difiere cuando se encuentren inmersos en la comisión de delitos no amnistiables, el Estado podría eventualmente renunciar a la persecución penal, decisión que será de competencia de la Sala de Definición de Situaciones Jurídicas de la JEP ${ }^{15}$ (numeral 10 art. 28 de ley 1820 de 2016).

Con ello observado, si bien por un lado se reconoce la calidad de víctimas de las personas menores de edad, por el otro se asume la potestad estatal de persecución y juzgamiento, manteniéndose, a pesar del proceso transicional, la disyuntiva de calidad de víctimas y victimarios, siendo una construcción diferencial en este último caso la realización de un protocolo plenamente establecido para la reincorporación de los NNA, el cual lamentablemente dista de su eficacia al no contar con la voluntad política de los actores en confrontación y la visibilización de la importancia de los menores como sujetos de construcción de una paz estable y duradera.

\section{Responsabilidad adolescente en su calidad dual victi- mas-victimarios}

Ante la clara disyuntiva punitiva-proteccionista que se ha generado frente a los NNA vinculados a grupos armados, tanto en los contextos de justicia ordinaria como en los procesos de justicia transicional vivenciados en Colombia, es necesario determinar si la responsabilidad penal adolescente resulta una alternativa viable para la satisfacción y restablecimiento de los derechos de la adolescencia involucrada en el conflicto, a la luz de los principios de la capacidad progresiva de ejercicio de derechos y del de interés superior del niño/a.

A continuación, se buscará la concreción práctica de los mentados principios en conexión directa con el conflicto armado colombiano, para arribar finalmente a la construcción de escenarios de responsabilidad que permitan una adecuada ponderación

15. Además de esta Sala y una Secretaria Ejecutiva, la JEP está compuesta por: 1. La Sala de Reconocimiento de Verdad Oy Responsabilidad y de Determinación de los Hechos y Conductas; 2. La Sala de Amnistía e Indulto; 3. La Unidad de Investigación y Acusación; y 4. El tribunal para la Paz. 
entre la calidad de víctimas del delito de reclutamiento forzado que ostentan los NNA y los derechos de terceros víctimas del accionar del grupo al cual pertenecen.

\section{Capacidad progresiva de ejercicio de derechos}

La construcción del paradigma de las NNA como sujetos titulares de derechos, generó la necesidad de establecer en qué forma estas prerrogativas pueden ser ejercidas de forma autónoma por los propios NNA (Art. $5 \mathrm{CDN})^{16}$. Es en este marco que se postula el reconocimiento de la capacidad progresiva de los NNA, a fin de que puedan ejercer - personalmente- sus derechos bajo el entendido que "a medida que los niños adquieren competencias cada vez mayores, disminuye su necesidad de orientación y dirección, y aumenta su capacidad de asumir responsabilidades tomando decisiones que afectan su vida" (Guillo, 2011, p. 210).

En consecuencia, el desarrollo jurídico se ha esforzado por concretizar este principio, pudiéndose destacar lo precisado por Barcia al considerar que la capacidad se determina conforme a los criterios de edad, madurez y la entidad del derecho afectado (Barcia, 2013, p. 18 y ss), los cuales brindan materialidad al principio de capacidad progresiva, siendo en todo caso necesario llevarse a cabo un análisis particular frente a cada sujeto menor de edad en uso de dichas garantías.

En tal sentido, debemos tener en cuenta que cuando hablamos de la edad del sujeto nos referimos al hecho natural utilizado por el derecho para categorizar y otorgar capacidades, por lo que desde un análisis formal pudiésemos afirmar que a mayor sea la edad del sujeto, mayor será su

"facultas agendi, en virtud de la cual el sujeto tiene poder para concluir actos válidos y eficaces en la esfera del Derecho. Así pues, la capacitas representa, en definitiva, el paso de la potencialidad a la actuación, y de la mera existencia del derecho a su realización mediante el comportamiento humano". (Ravetllat, 2015, p. 130)

Al respecto, al analizar este criterio en el contexto del conflicto armado colombiano, es posible evidenciar que el fenómeno del reclutamiento forzado se genera desde los 7 a 17 años, siendo el promedio de 12.8 años. Por este motivo, este fenómeno se lleva a cabo en una edad fundamental en la que "se replantea la definición personal y social del ser humano a través de una segunda individuación que moviliza procesos de exploración, diferenciación del medio familiar, búsqueda de pertenencia y sentido de vida" (Krauskopof, 1999, p. 25).

Ahora bien, no obstante la importancia del factor etario, el análisis de la capacidad requiere a su vez la comprensión acerca de las condiciones de madurez, las cuales están íntimamente ligadas a las vivencias diferenciadas en los contextos culturales y sociales en los que se desarrollan los NNA. Particularmente, al analizar el contexto en el que los individuos víctimas de reclutamiento forzado se encuentran enraizados, es posible evidenciar que incluso desde su fase previa al reclutamiento su ámbito de vida se caracteriza por la exclusión, marginalidad y extrema pobreza a la que están sometidos, mientras que durante su vinculación al grupo armado, se desarrollan en un ambiente guiado bajo la dinámica propia de regímenes castristas en el que se les somete a una serie de prácticas que, como lo resume Springer (2012):

16. En este sentido se determina la capacidad y facultad de los niños/as para ejercer (con grados crecientes de independencia) sus derechos frente a derecho-deber de los padres o adultos responsables de dirección y orientación. Correa Y Vargas (2011), p. 182. 
"buscan alienar las conciencias en formación a través de una socialización perversa y sectaria que sustituye un desarrollo moral precario por la rutinización de la violencia. Estas prácticas no solamente cumplen con el objetivo de convertir en absoluta e incuestionable la autoridad de los comandantes y superiores, sino también el de erradicar, por la vía del miedo y el trauma, la estructura emocional de estos niños y niñas y subvertirla, suplantarla por patrones antisociales". (p. 40)

En último lugar, es importante analizar la entidad del derecho afectado atendiendo al "hecho de que las facultades del niño pueden -también- diferir según la naturaleza de los derechos ejercidos" (Guillo, 2011, p. 210), precisión correspondida por Barcia (2013) al considerar que "a mayor entidad del acto, con relación a los derechos fundamentales más esenciales, o a mayor peligrosidad, mayor será el grado de edad y madurez que el ordenamiento jurídico debe exigir al niño o adolescente para reconocer su autonomía" (p. 23).

Frente a este criterio es posible determinar que tanto la vinculación al grupo armado como las actuaciones propias de los regímenes castristas, ponen en constante riesgo la integridad personal y vulneran sistemáticamente los derechos fundamentales de la infancia y adolescencia reclutada, exigiendo por tanto un grado de madurez tan alto que como se observó en párrafos anteriores no se evidencia en esta población.

Es precisamente la observación de los criterios que determinan la capacidad en la infancia y adolescencia víctima de reclutamiento forzado lo que nos permite considerar la existencia de la alienación de todos los derechos de los NNA reclutados, el despojo de sus libertades y de su dignidad humana, parámetros que nos dirigen a la ineludible afirmación de que el contorno les impide adquirir las facultades "que les permitan decidir cuándo y cómo quieren ejercer un determinado derecho, como asimismo la posibilidad de que en un momento determinado decidan no ejercerlo" (Correa Y Vargas, 2011, p. 182), premisa bajo la cual se elimina también su capacidad de asumir la responsabilidad derivada de los actos que realicen durante su vinculación a los grupos armados.

\section{Interés superior del niño}

Por otro lado, el principio del interés superior del niño, como lo expresa Ravetllat (2012), "pone acertadamente el acento en -la realidad de los individuos menores de edad- como sujetos dignos de atención, promoción, provisión y protección. Este criterio ha de aplicarse en todas aquellas situaciones o conflictos donde se hallen involucrados menores de edad" (p. 98), principio que no persigue otra cosa que la garantía real y efectiva de todos los derechos de los que son titulares.

Por su parte, la Observación General No 14 del Comité de Derechos del Niño/a ha identificado el interés superior de la niña/o desde una triple naturaleza jurídica, como a) un derecho sustantivo de que su interés sea una consideración primordial en todas las decisiones que afecten a un NNA o grupo de NNA; b) como principio jurídico interpretativo fundamental, considerando que "si una disposición jurídica admite más de una interpretación, se elegirá la interpretación que satisfaga de manera más efectiva el interés superior del niño/a" ; c) como una norma de procedimiento a través de la cual "el proceso de adopción de decisiones deberá incluir una estimación de las posibles repercusiones (positivas o negativas) de la decisión en el niño/a o los niños/ as interesados", con sus respectivas garantías procesales (Comité de Derechos del Niño, 2013, párr. 6.). 
No obstante lo anterior, la Observación General No. 14 del Comité de derechos del niño/a reconoce que el interés superior del niño/a es un "concepto dinámico que abarca diversos temas en constante evolución" (Comité de Derechos del Niño, 2013, párr. 11.), y que al ser flexible y adaptable requiere de un análisis sobre la situación concreta y las necesidades personales de el o los NNA afectados. Así, como afirma Aguilar, diversos son los elementos que incorpora el interés superior del niño/a, a saber, "la dignidad del ser humano; las características propias de las niñas/os o ponderar las características particulares de la situación en la que se halla el niño/a; la necesidad de propiciar el desarrollo de los niños/as, con pleno aprovechamiento de sus potencialidades" (Aguilar. 2008, p. 245).

En este sentido cuando nos encontramos ante decisiones de la administración estatal, la correcta aplicación del principio requiere, como lo manifiesta Cillero (1998), de

"un análisis conjunto de los derechos afectados y los que se puedan afectar por resolución de la autoridad -es así que- siempre ha de tomarse aquella medida que asegure la máxima satisfacción de los derechos que sea posible y la menor restricción de ellos, esto no solo considerando el número de derechos afectados, sino también su importancia relativa". (p.83)

Son precisamente estas consideraciones, las que nos permiten afirmar que la aplicación del interés superior del niño en el caso de los NNA vinculadas al conflicto armado colombiano, exigen su consideración exclusiva como víctimas, descartando por tanto la asignación de la condición de victimarios ${ }^{17}$.

Además, cuando nos referimos a la intervención estatal a través de su poder sancionador, el principio del interés superior del niño/a insta a "la disminución al mínimo posible-siempre perfectible- de la intervención a través de recursos «penales» sobre la adolescencia y la absoluta excepcionalidad de la medida de separación del niño/a de su entorno familiar" (Cillero, 1998, p. 83 ), ello como reconocimiento expreso de que este tipo de medidas que restringen la libertad personal y privan su desarrollo en el entorno familiar, obstaculizan sistemáticamente el ejercicio de otros derechos que se hacen imposibles de satisfacer en privación de la libertad.

Por su parte, el ordenamiento jurídico colombiano contempla un programa especializado de protección para los menores de edad desvinculados de los grupos insurgentes $^{18}$, el cual se constituye en un mecanismo alternativo a la judicialización, representando por tanto una menor injerencia y limitación de sus derechos fundamentales. Tal situación implica que, con base en la garantía efectiva del principio de interés superior del niño/a, las distintas autoridades estatales deben aplicar las directrices centrales de esta prerrogativa, y en consecuencia, eliminar la calidad dual víctima-victimario que se ha generado hacia los NNA excombatientes, impidiendo su criminalización y la consecuente aplicación de las sanciones penales previstas para los adolescentes que hayan atentado, en contexto de conflicto armado, contra el ordenamiento jurídico.

Por último, es necesario considerar que la aceptación de la responsabilidad penal de los NNA vinculadas al conflicto armado, además de infringir los postulados del interés superior del niño/a, adicionalmente produce un incentivo malévolo para su 17. En este sentido el Comité de los Derechos del Niño/a ha reiterado su preocupación por las denuncias presentadas sobre el procesamiento penal de niños, niñas y adolescentes reclutados por los grupos al margen de la ley-especialmente por las BACRIM-, en lugar de ser tratados como víctimas de este delito. (Comité de los Derechos del Niño/a, 2015).

18. Al respecto véase el "Lineamiento técnico de las modalidades del programa de atención especializada para el restablecimiento de derechos a niños, niñas y adolescentes víctimas de reclutamiento ilícito, que se han desvinculado de grupos armados organizados al margen de la ley y contribución a proceso de reparación integral". (Instituto Colombiano de Bienestar Familiar, 2016) 
no desvinculación oficial, esto por cuanto ante la posibilidad de enfrentar un proceso penal, la alternativa de su salida extraoficial de los campamentos de los grupos armados resulta atractiva y sin aparentes consecuencias jurídicas. Ello claro está, surge desde una visión sesgada en tanto se invisibiliza las consecuencias inmediatas de tal decisión que se centran en la pérdida de los beneficios jurídicos propios de su calidad de desmovilizados, como de aquellos derivados del proceso de restablecimiento de sus derechos en su condición de víctimas del delito de reclutamiento forzado. Paralelamente ello los convierte en sujetos vulnerables frente a nuevas situaciones de reclutamiento -tal como aconteció con las bandas criminales emergentes o BACRIM- así como a posibles actos de retaliación.

\section{Hacia la construcción de una teoría alternativa a la responsa- bilidad}

Hasta el momento hemos vislumbrado que a partir de los principios de la capacidad progresiva e interés superior del niño/a, la carga de responsabilidad penal frente a la adolescencia víctima del reclutamiento forzado es evidentemente errónea. No obstante, es necesario consolidar una fórmula teórica capaz de sostener y unificar no solo estos dos principios, sino también proyectarse como una herramienta material de efectivización, tanto de los derechos sustantivos atribuidos a los NNA víctimas del conflicto, como de aquellos derechos de terceros víctimas del conflicto armado.

Es en este sentido, que hemos encontrado en lo que he denominado la "teoría de la aleatoriedad" el mecanismo garantista a través del cual se evidencia la falacia en la que incurre la responsabilidad penal de los adolescentes vinculados al conflicto armado colombiano, en tanto se encuentra sustentada en factores que, pese a ser ajenos a la esfera volitiva del sujeto menor y por tanto no previsibles más que por la intervención del azar (valga decir, la edad al momento de la comisión del delito y la magnitud del mismo), se convierten en trascendentales componentes a la hora de determinar tanto su responsabilidad penal como su tratamiento criminal.

Ciertamente, se considera aleatoria por cuanto la responsabilidad penal se erige sobre factores como la edad en la que el sujeto es reclutado, así como la edad en la que es coaccionado a la comisión del delito. Así, por ejemplo, cuando el sujeto es reclutado siendo menor de 14 años y la comisión del delito se genera igualmente siendo menor de 14 años, éste adquiere la calidad exclusiva de víctima, sin lugar a enfrentar procesos de responsabilidad penal -por considerarse inimputable-. Sin embargo, cuando el sujeto independientemente de la edad en la que es reclutado, comete el delito siendo mayor de 14 años, se le atribuye la condición dual víctima-victimario, pudiendo por tanto enfrentar el ius punendi del Estado.

Dicha aleatoriedad en igual sentido acontece respecto a la magnitud del delito cometido, esto es, si el acto tipificado se acopla a la gama de delitos contemplados como conexos -o políticos-, o si por el contrario se encuentra tipificado como delito de lesa humanidad o crimen de guerra. Así pues, pese a que el sujeto es ajeno a la determinación de la conducta que ha de ejecutar, y tampoco le es posible negarse a la comisión de la misma, el ordenamiento jurídico colombiano otorga tratamiento diferencial cuando el individuo realiza una acción constitutiva de delito político o conexo (permitiéndose aplicarle el principio de oportunidad en contextos de justicia ordinaria, mientras en procesos de justicia transicional son sujetos de amnistía), caso contrario a lo ocurrido si la conducta es constitutiva de delito de lesa humanidad o crimen de guerra, en donde, respetando los límites impuestos desde el derecho internacional 
humanitario y los lineamientos de la Corte Penal Internacional, se exige al sujeto criminal el enfrentamiento de un proceso judicial de responsabilidad penal sin posibilidad de acceder a los mencionados beneficios.

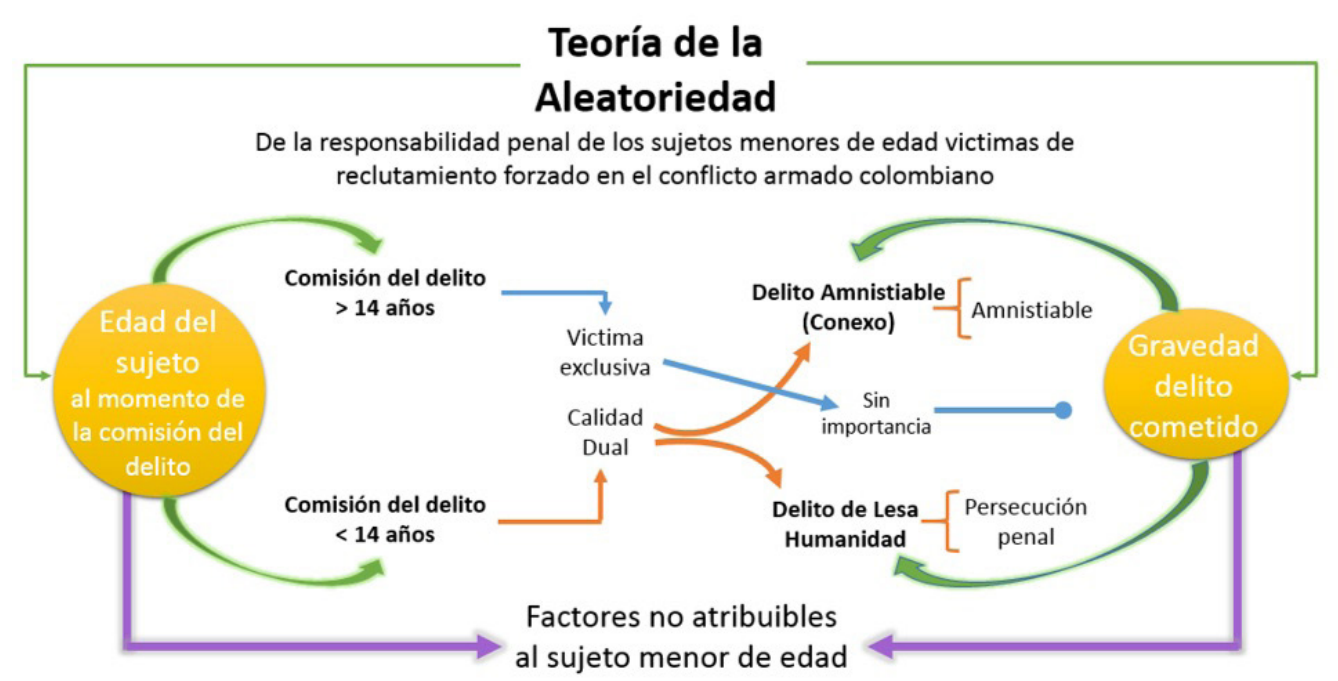

Figura 1. Teoría de la Aleatoriedad

Bajo este entendido, la responsabilidad penal que se atribuye a los adolescentes excombatientes se sustenta en un análisis formal de los criterios de edad y magnitud del delito cometido, lo cual contraviene abiertamente los postulados derivados de los principios del interés superior del niño/a y capacidad progresiva de ejercicio de derechos, así como los demás lineamientos que inspiran el modelo de protección integral, ello por cuanto no hace eco frente a la real concreción del ejercicio de voluntad que un sujeto menor de edad posee al momento de cometer el ilícito, siendo igualmente indistinta la caracterización de factores que agravan el tipo penal, haciendo de estas instrucciones ajenas al análisis material de la capacidad y volición del sujeto menor de edad.

Ante lo mencionado, es necesario precisar que no es nuestra intención negar que durante su afiliación a los grupos insurgentes, los NNA pueden cometer actos constitutivos de delitos -incluso aquellos de la mayor gravedad-, no obstante lo que se cuestiona es la pretensión de atribuirles una responsabilidad de tipo punitivo, puesto que constituiría una paradoja afirmar que, por un lado, los NNA víctimas del reclutamiento forzado han sido privados del ejercicio autónomo de sus derechos, mientras que paralelamente se propende por responsabilizarles de los actos que realizan durante su afiliación al grupo armado -aún cuando se han ejercido sin consideración a su voluntad-. Se consolida entonces desde el derecho penal moderno una teoría contradictoria que minimiza, o mejor, elimina de facto su capacidad, mientras in limine maximiza su responsabilidad.

Por otra parte, vale la pena tener en cuenta que, "la sola existencia del conflicto armado rompe el estado de condiciones normales -tanto- fácticas como jurídicas de una sociedad y por ende requieren igualmente una respuesta jurídica extraordinaria acorde con las condiciones especiales del conflicto" (Villalva, 2012, p. 70), máxime cuando se trata de una población que ha sido expuesta a los más extremos escenarios de vulnerabilidad y a la transgresión sistemática de sus derechos humanos, razones suficientes para considerar arbitraria la asignación de la calidad dual víctima-victimario. 
En este sentido, inmersos en la búsqueda de la reivindicación de los derechos de los NNA involucrados en conflictos armados, no se puede encontrar otro fin más certero que el generado a través de la eliminación de la doble calidad víctima-victimario que el ordenamiento jurídico colombiano actualmente les ha asignado.

Un último aspecto a tomar en consideración, radica en la circunstancia de que, si bien hemos afrontado la calidad de víctimas de los NNA, ante la aplicación de la teoría de la aleatoriedad que excluye su responsabilidad penal, lo cierto es que desde una posición antagónica se ubican los derechos de las víctimas a la verdad, justicia y reparación ante las consecuencias dañinas del accionar violento de los NNA vinculados a los grupos armados ilegales, los cuales como lo plantea Alexy (2014) "no solo exigen la mayor realización posible en relación con las posibilidades fácticas, sino también la mayor realización posible con las posibilidades jurídicas" (p. 529).

En concordancia a lo anterior, es necesario considerar que a pesar de que la categorización a partir de "edad y magnitud del delito cometido" no son óbice para la criminalización de los agentes menores de edad, estos factores pueden ser considerados para la consolidación de un proceso administrativo en búsqueda, entre otras, de garantías frente la memoria histórica, reparación administrativa y simbólica, acciones de perdón y revelación de la verdad ${ }^{19}$. Al efecto, hemos arribado a la concreción de tres tipologías de víctimas de reclutamiento forzado, a saber: a) victimas exclusivas 1 ; b) victimas exclusivas 2; y c) calidad dual. Procedemos, acto seguido, a detallar brevemente sus características identificadoras.

Inicialmente, encontramos la tipología de «Víctimas exclusivas 1 » que corresponde a las personas reclutadas forzadamente que han realizado una conducta constitutiva de delito siendo menores de 14 años. Frente a esta categoría nos adherimos a lo establecido por el ordenamiento jurídico colombiano que les asigna la calidad exclusiva de víctimas en tanto ostentan la condición de inimputables. De ello deriva que el tratamiento que ha de brindárseles es exclusivamente el de restablecimiento de sus derechos.

Paralelamente, encontramos la tipología «Victimas exclusivas 2», la cual incluye a las personas que hubiesen cometido delitos durante su militancia en el grupo armado siendo mayores de 14 y menores de 18 años. Frente a esta categoría, rechazamos la asignación de la calidad dual que les otorga el sistema colombiano, exigiendo para ellos una extensión de inimputabilidad atendiendo a los postulados de la teoría de la aleatoriedad ut supra mencionados.

A pesar de lo anterior, la eliminación de la responsabilidad penal de los adolescentes ex combatientes, no implica que no puedan contemplarse mecanismos alternativos a los recursos penales, mediante los cuales contribuyan al esclarecimiento de los hechos y la reparación simbólica en un intento por salvaguardar al máximo los derechos de los terceros victimas de sus actuaciones. Es menester considerar además que si bien la anterior postura se desliga de las consecuencias penales, ello no autoriza el desconocimiento de las garantías propias del debido proceso que garanticen un adecuado tratamiento al sujeto menor de edad.

Finalmente, se constituye la tipología «Dual víctima-victimario» en la que se incluye a aquellas personas que habiendo sido reclutadas menores de edad, cometen delitos una vez alcanzada la mayoría de edad. Esta última tipología podrá considerarse la

19. Configurando una justicia «anamnética» entendida como "una construcción teórica basada en la memoria como forma de justicia para las víctimas y que dota de complementariedad los contenidos de la justicia transicional". (Rúa, 2016, p. 460). 
más controvertible bajo la tesis de la aleatoriedad, en tanto es igualmente complejo el análisis del factor volitivo de sus acciones, sin embargo el descartar prima facie el accionar del ius punendi podría significar un detrimento absoluto de los derechos de las víctimas del conflicto, dejando en impunidad total la vulneración de sus derechos por cuanto todos los actores del conflicto pudiesen alegar el hecho del reclutamiento forzado como escudo en contra de la responsabilidad penal.

Tal procedimiento de responsabilidad penal debe, sin embargo, prestar una especial consideración al impacto del fenómeno de reclutamiento forzado del sujeto en el desarrollo de sus capacidades, favoreciendo consecuentemente la aplicación de medidas que restrinjan en la menor proporción sus derechos y libertades.

En suma, es necesaria la construcción de herramientas que permitan concretizar la aplicación de principios como el de interés superior del niño/a y capacidad progresiva a fin de evitar mayores desagravios (como la victimización secundaria) en contra de la infancia y adolescencia sistemáticamente invisibilizada, ello sin desconocer que el alcance de un efectivo restablecimiento de derechos y la consecuente reincorporación a la vida civil, exige además un compromiso político, humano y económico por parte de todos los actores involucrados.

\section{A modo de conclusión}

1. Con el cambio paradigmático que implicó el reconocimiento de los NNA como sujetos titulares de derecho y con capacidad progresiva para ejercerlos, se generó también una atribución de responsabilidad derivada de sus acciones, según la cual a mayor capacidad se genera proporcionalmente un mayor grado de responsabilidad. No obstante tal afirmación, y desde un análisis del contexto del conflicto armado colombiano, se desprende que a los NNA víctimas del reclutamiento forzado se les ha impedido consolidar las competencias para ejercer esa capacidad progresiva, hecho que impide endilgar una responsabilidad de sus actos, mucho menos aquellos de tipo punitivo, ello además si consideramos que el interés superior del niño/a propugna la limitación al máximo del ius punendi del Estado -cuando hablamos de personas menores de edad-, y máxime cuando se trata de sujetos a los que se les ha vulnerado sistemáticamente sus derechos, y en el que la responsabilidad penal no sería otra cosa que su victimización secundaria desde la misma institucionalidad.

2. Concluimos, desde el marco de la "teoría de la aleatoriedad", que la responsabilidad penal presente en el ordenamiento jurídico colombiano se fundamenta en una falacia, al considerar factores como la edad y magnitud del delito cometido como criterios fundamentales frente al tratamiento criminal irrogado a los NNA, pese a ser ajenos a su esfera volitiva. Por otra parte, si bien es cierto dichos criterios no deben ser empleados para asignarles una responsabilidad de tipo punitivo, desde un necesario ejercicio ponderativo con los derechos de las víctimas -que se contraponen y aparecen incluso como antagónicos a los derechos de las personas menores de edad víctimas del reclutamiento forzado- hemos esbozado una teoría y una categorización que permite, más allá de la responsabilidad penal, lograr el máximo resguardo de los derechos a la verdad y a la reparación. En este entendido se han generado las categorías de "victima exclusiva 1", "victima exclusiva 2" y finalmente "victima de calidad dual", las cuales consideramos parámetros frente a la ejecución de políticas de administración de justicia en el proceso transicional de la JEP. 
3. Entendemos que, promulgada la exclusión de la responsabilidad penal, ello no debiere implicar automáticamente que se genere una actitud inmóvil u omisiva por parte del Estado. Por el contrario, consideramos que el Estado debiera dotarse de más recursos, tanto materiales como humanos, a fin de que pueda evidenciarse ciertamente ese restablecimiento de derechos sistemáticamente vulnerados, lo cual -en énfasis- no puede hacerse desde escenarios punitivos, sino desde estadios que realmente garanticen esa resocialización de las personas menores de edad, siendo también un llamado a visibilizar la importancia de los niños, niñas y adolescentes en la construcción de una verdadera paz estable y duradera.

\section{Bibliografia}

Acuerdo Final. (2016). Acuerdo Final para la terminación del conflicto y la construcción de una paz estable y duradera. Recuperado de http://www.altocomisionadoparalapaz.gov. co/procesos-y-conversaciones/Documentos\%20compartidos/24-11-2016NuevoAcuerdoFinal.pdf

Aguilar Cavallo, G. (2008). El principio del interés superior del niño y la Corte Interamericana de Derechos Humanos. Revista Estudios Constitucionales (Año 5, $\left.N^{\circ} 1\right), 223-247$.

Alexy, R. (2014). Teoría de los derechos fundamentales (Traducc. Carlos Bernal Pullido), Madrid: Centro de Estudios Políticos y Constitucionales.

AUC. (1998). Estatuto de constitución y régimen disciplinario. Recuperado de http:// autodefensasgaitanistasdecolombia.org/agc2/index.php/32-uncategorised/63-estatutos-de-constitucion-y-regimen-disciplinario

Bacares Jara, C. (2015). Los niños, niñas y jóvenes desvinculados de los grupos armados ilegales de Colombia: ¿Victimas de la violencia política o sujetos del delito? En: Revista Estudios Socios-jurídicos (Año 17, № 2), 233-262.

Barcia Lehmann, R. (2013). La capacidad extrapatrimonial de los niños y adolescentes conforme a sus condiciones de madurez. Revista lus et Praxis (Año 19, N² 2), 2-52.

Beloff, M. (1998). "Los sistemas de responsabilidad penal juvenil en América Latina". En: E. García (Ed.), Infancia, Ley y Democracia en América Latina (pp. 87-107). Bogotá: Editorial Temis.

Capello Valle, C. (2013). La especialidad en la responsabilidad penal adolescente. Revista de la Defensoría Penal Pública (N93), 35-37.

Castro Gutiérrez, M y Hernández Vidal, J. (2010). Los derechos de la infancia y la adolescencia en Colombia como sistema constitucional. Bogotá: Editorial Digiprint Editores EU.

Centro Nacional de Memoria Histórica. (2012). Informe General Basta Ya. Recuperado de http://www.centrodememoriahistorica.gov.co/descargas/informes2013/bastaYa/basta-ya-memorias-guerra-dignidad-new-9-agosto.pdf

Cillero Bruñol, M. (1998). "El interés Superior del Niño en el marco de la Convención Internacional sobre los derechos del Niño". En: E. García (Ed.), Infancia, Ley y Democracia en América Latina (pp. 70-85). Bogotá: Editorial Temis. 
Cillero Bruñol, M. (2013). Infancia, autonomía y derechos: una cuestión de principios. Recuperado de http://educacioninicial.mx/wp-content/uploads/2013/11/A001.pdf

Comisión Colombiana de Juristas. (2007): Anotaciones sobre la ley de justicia y paz: Una mirada desde los derechos de las víctimas. Recuperado de http://www.coljuristas.org/documentos/libros e informes/anotaciones sobre la ley de justicia_y_paz.pdf

Comisión Interamericana de Derechos Humanos. (2002). Opinión Consultiva OC-17/2002, Condición Jurídica y Derechos Humanos del Niño. Recuperado de http://www. corteidh.or.cr/docs/opiniones/seriea 17 esp.pdf

Comité de los Derechos del Niño/a. (2008). Examen de los informes presentados por los Estados partes con arreglo al artículo 8 del Protocolo facultativo de la Convención sobre los Derechos del Niño relativo a la participación de niños en los conflictos armados. Informes iniciales que los Estados partes debían presentar en 2007. Recuperado de https://tbinternet.ohchr.org/ layouts/15/treatybodyexternal/Download.aspx?symbolno=CRC\%2fC $\% 2 f O P A C \% 2 f C O L \% 2 f 1 \& L a n g=e s$

Comité de los Derechos del Niño/a. (2010). Examen de los informes presentados por los Estados partes en virtud del artículo 8 del Protocolo facultativo de la Convención sobre los Derechos del Niño relativo a la participación de niños en los conflictos armados. Recuperado de https://tbinternet.ohchr.org/ layouts/15/treatybodyexternal/ Download.aspx?symbolno=CRC\%2fC\%2fOPAC\%2fCOL\%2fCO\%2f1\&Lang=es

Comité de los Derechos del Niño/a. (2013). Observación general No 14 sobre el derecho del niño a que su interés superior sea una consideración primordial (artículo 3, párrafo 1). Recuperado de https://www.observatoriodelainfancia.es/ficherosoia/ documentos/3990 d CRC.C.GC.14 sp.pdf

Comité de los Derechos del Niño/a. (2015). Observaciones finales sobre los informes periódicos cuarto y quinto combinados de Colombia. Recuperado de https:// tbinternet.ohchr.org/ layouts/15/treatybodyexternal/Download.aspx?symbolno=CRC $\% 2 f C \% 2 f C O L \% 2 f C O \% 2 f 4-5 \&$ Lang=es

Consejo de Seguridad de las Naciones Unidas. (2012). Informe del Secretario General sobre los niños y el conflicto armado en Colombia S/2012/171. Recuperado de http://www.un.org/es/comun/docs/?symbol=s/2012/171

Consejo de Seguridad de las Naciones Unidas. (2016). Informe del Secretario General sobre los niños y los conflictos armados en Colombia (septiembre de 2011 a junio de 2016)". Recuperado de http://www.un.org/es/comun/docs/?symbol=S/2016/837

Consejo Nacional de Política Económica y Social República de Colombia Departamento Nacional de Planeación. (2010). Política de prevención del reclutamiento y utilización de niños, niñas, adolescentes por parte de los grupos armados organizados al margen de la ley y de los grupos delictivos organizados. Recuperado de http:// www.mintic.gov.co/portal/604/articles-3509 documento.pdf

Corral Talciani, H. (2008). Los métodos particulares de la investigación jurídica, en "Cómo hacer una tesis en derecho - Curso de metodología de la investigación Jurídica. Santiago: Editorial jurídica de Chile. 
Correa Camus, P., y Vargas Pavez, M. (2011). La voz de los niños en la justicia de familia de chile. Revista lus et Praxis, (Año 17, N 1), 177-204.

Corte Constitucional Colombia. (2005). Sentencia C-203. M.P. Manuel José Cepeda Espinosa.

Corte Constitucional Colombia. (2006). Sentencia C-370. M.P. Manuel José Cepeda Espinosa.

Corte Constitucional Colombia. (2009). Sentencia C-240. M.P. Mauricio González Cuervo.

Corte Constitucional Colombia. (2013). Sentencia C-579. M. P. Jorge Ignacio Pretelt.

Corte Constitucional de Colombia. (2008). Auto 251. M.P. Manuel José Cepeda Espinosa.

Couso Salas, J. (1999). "Problemas teóricos y prácticos del principio de separación de medidas y programas, entre la vía penal-juvenil y la vía de protección especial de derechos". En: A.A.V.V., Justicia y derechos del niño (pp. 79-104). Santiago: UNICEF Argentina, Chile y Uruguay.

De La Válgoma, M. (2013). Padres sin derechos hijos sin deberes: el laberinto jurídico de la infancia. Barcelona: Editorial Ariel.

Defensoría del Pueblo de Colombia. (2006). Caracterización de las niños, niñas y adolescentes desvinculados de los grupos armados ilegales: inserción social y productiva desde un enfoque de derechos humanos. Recuperado de https://www.unicef.org/ colombia/pdf/Boletin-defensoria.pdf

Defensoría del Pueblo de Colombia. (2014). Prevención del reclutamiento de niños, niñas y adolescentes. Análisis de la política pública con enfoque étnico. Recuperado de http:// studylib.es/doc/7249532/prevenci\%C3\%B3n-del-reclutamiento-de-ni\%C3\%B10s--ni\%C3\%B1as-y-adolescentes

Di Pietro, A. (1999). Derecho privado romano. Buenos Aires: Editorial Depalma.

Dirección Nacional de Análisis y Contextos -DINAC-. (2016). Informe de reclutamiento ilícito de las FARC-EP. Recuperado de http://www.fiscalia.gov.co/colombia/noticias/destacada/las-farc-reclutaron-ilicitamente-a-11-556-menores-desde1979-fiscal-e-jorge-perdomo/

Duce, M. (2009). El derecho a un juzgamiento especializado de los jóvenes infractores en el derecho internacional de los derechos humanos y su impacto en el diseño del proceso penal juvenil. Revista lus et Praxis (Año 15, N 1), 73 - 120.

DUNCAN, G. (2016). “Exclusión, insurrección y crimen”. En: E. Pizarro, Una lectura múltiple y pluralista de la historia. Recuperado de http://www.altocomisionadoparalapaz. gov.co/mesadeconversaciones/PDF/una-lectura-multiple-y-pluralista-de-la-historia-1447178719-1460381905.pdf 
Fals Borda, O; Guzmán, G; y Umaña Luna, E (2005). La violencia en Colombia. Bogotá: Editorial Taurus.

Fanlo, I. (2004). Derechos de los niños: una contribución teórica. Mexico: Editorial Fontamara.

Ferrajoli, L. (1995). Derecho y Razón. Teoría del garantismo penal. Madrid: Editorial Trotta.

García Sayán, D., y Giraldo Muñoz, M. (2016). Reflexiones sobre los procesos de justicia transicional. Revista Journal of International Law 7, (N²), 96-143.

Giraldo, J. (2016)." Política y guerra sin compasión". En: E. Pizarro, Una lectura múltiple y pluralista de la historia. Recuperado de http://www.altocomisionadoparalapaz. gov.co/mesadeconversaciones/PDF/una-lectura-multiple-y-pluralista-de-la-historia-1447178719-1460381905.pdf

Gobierno Nacional y FARC-EP. (2016). Comunicado Conjunto No. 70. Recuperado de http://www.altocomisionadoparalapaz.gov.co/mesadeconversaciones/PDF/comunicado-conjunto-70-15-de-mayo-de-2016-1463349969.pdf

Gómez Velásquez, A., y Correa-Saavedra, J. (2015). ¿Sobredimensión de la tensión entre justicia y paz? Reflexiones sobre justicia transicional, justicia penal y justicia restaurativa en Colombia. Revista Colombiana de Derecho Internacional (N²6), 193-247.

Guilló Jiménez, J. (2011). "Políticas de infancia". En: I. Ravetllat (Ed.), Derecho de la persona (Barcelona, Editorial Bosch) pp. 206-245.

Gutiérrez, F. (2016). “¿Una historia simple?”. En: E. Pizarro. Una lectura múltiple y pluralista de la historia. Recuperado de http://www.altocomisionadoparalapaz.gov. $\mathrm{co/mesadeconversaciones/PDF/una-lectura-multiple-y-pluralista-de-la-histo-}$ ria-1447178719-1460381905.pdf

Hernandez Delgado, E. (2001). Los niños y las niñas frente al conflicto armado colombiano. Recuperado de http://www.redalyc.org/pdf/110/11000607.pdf

Human Rights Watch (2003). Aprenderás a no llorar: Niños Combatientes en Colombia. Recuperado de https://www.hrw.org/legacy/spanish/informes/2003/colom$\underline{\text { bia ninos.pdf }}$

Instituto Colombiano de Bienestar Familiar. (2016). Lineamiento técnico de las modalidades del programa de atención especializada para el restablecimiento de derechos a niños, niñas y adolescentes víctimas de reclutamiento ilícito, que se han desvinculado de grupos armados organizados al margen de la ley y contribución al proceso de reparación integral- Resolución No. 1525 de 2016. Recuperado de http://www. icbf.gov.co/portal/page/portal/PortallCBF/procesos/misionales/proteccion/ restablecimiento-derechos/LM12.P\%20Lineamiento\%20T\%C3\%A9cnico\%20 Programa\%20Atenci\%C3\%B3n\%20Especializada\%20a\%20Ni\%C3\%B1os\%20 Ni\%C3\%B1as\%20y\%20Adolescentes\%20V\%C3\%ADctimas\%20de\%20Reclutamiento\%20llicito\%20Desvinculados\%20v1.pdf 
Krauskopof, D. (1999). El desarrollo psicológico en la adolescencia: las transformaciones en una época de cambios. Revista. Adolescencia y salud 1, (N. 2), 23-31.

Lamo, J.: Escudero, J; Robledo, A; Frigola, J. (2000). El proceso penal. Barcelona: Editorial Bosch.

Londoño Ayala, C. A. (2010). Bloque de Constitucionalidad. Bogotá: Editorial Nueva Jurídica.

Lucero Pantoja, J. (2012). Cara o sello. La decisión crucial en la justicia transicional. Saarbrucken: Editorial Académica Española.

Medina Gallego, C. (2007). Ejército de Liberación Nacional notas para una historia de la ideas políticas, Recuperado de http://www.cedema.org/uploads/Medina Gallego ELN.pdf

Observatorio de paz y conflicto. (2015). Cifras de menores de edad desvinculados entre 1999 y 2015. Recuperado de http://www.humanas.unal.edu.co/observapazyconflicto/ddr-en-cifras/

Observatorio de paz y conflicto. (2016). Niños, Niñas y Adolescentes Vinculados al Conflicto Armado en Colombia Observatorio de Paz y Conflicto. Tratamiento en la Jurisdicción Penal Especial de Justicia y Paz. Recuperado de http://repository.oim.org. co/bitstream/20.500.11788/1308/2/COL-OIM0521.pdf

Observatorio de Procesos de Desarme, Desmovilización y Reintegración. (2010). Los procesos de Desarme, Desmovilización y Reintegración: buenas prácticas y retos. Recuperado de http://www.bdigital.unal.edu.co/1570/1/0DDR Buenas practicas y retos mayo 2010.pdf

Organización de las Naciones Unidas. (1949). Convenio IV de Ginebra relativo a la Protección de Personas Civiles en Tiempo de Guerra. Recuperado de http://pdh. minjusticia.gob.cl/wp-content/uploads/2015/12/Convenio-de-Ginebra-Sobre-la-Protecci\%C3\%B3n-de-las-Personas-Civiles-en-Tiempos-de-Guerra-\%C2\%ABConvenio-IV\%C2\%BB-1949.pdf

Organización de las Naciones Unidas. (1985). Reglas mínimas de las Naciones Unidas para la administración de la justicia de menores, resolución 40/33. Recuperado de https://www.unicef.org/panama/spanish/7972.htm

Organización de las Naciones Unidas. (1989). Convención de los derechos del niño. Recuperado de http://www.un.org/es/events/childrenday/pdf/derechos.pdf

Organización de las Naciones Unidas. (1990). Reglas de las Naciones Unidas para la protección de los menores privados de libertad de 1990, resolución 45/113. Recuperado de http://www.dpp.cl/resources/upload/files/documento/fb3a20e2dd7 786d9c0a281284a4a20f5.PDF

Organización de las Naciones Unidas. (2000). Protocolo Facultativo de la Convención sobre los Derechos del Niño. Recuperado de https://www.unicef.org/spanish/ specialsession/documentation/documents/op se sp.pdf 
Organización Internacional del Trabajo. (1999). Convenio 182 sobre la prohibición de las peores formas de trabajo infantil y la acción inmediata para su eliminación. Recuperado de http://ministeriopublico.gob.pa/wp-content/multimedia/2016/10/ Convenio-182-de-la-OlT.pdf

Patiño Hurtado, R. O. (2015). Participación niños, niñas y adolescentes en la guerra: ¿víctimas o victimarios?. Revista Diálogos de Derecho y Política (Año 7, N 17), 5-26.

Petit, E. (1999). Tratado elemental de derecho romano. Buenos Aires: Editorial Universidad.

Ravetllat Ballest, I. (2013). La infancia y la adolescencia en Cataluña: retos y propuestas para avanzar en la aplicación de la Convención sobre los Derechos del Niño. Estudio a partir de las Observaciones efectuadas por el Comité de los Derechos del Niño. Revista Intervención psicoeducativa en la desadaptación social, 6. pp. 19-39.

Ravetllat Ballesté, I. (2012). El interés superior del niño: concepto y delimitación del término. Educatio Siglo XXI, 30 (N²) 89-108.

Ravetllat Ballesté, I. (2014). Aproximación histórica a la construcción socio jurídica de la categoría infancia. Bogotá: Editorial Universitat Politécnica de Valéncia.

Ravetllat Ballesté, I. (2015). ¿Por qué dieciocho años? La mayoría de edad civil en el ordenamiento jurídico civil español. Anales de la Cátedra Francisco Suárez, 49, 129-154.

Rojas Duque, R. V. (2016). La responsabilidad penal de los menores víctimas de reclutamiento en el conflicto armado interno colombiano. Recuperado de http://repository. unimilitar.edu.co/bitstream/10654/14717/3/RojasDuqueRosaVirginia2016.pdf

Rojas, J. (1993). Desplazamiento, Derechos Humanos y conflicto armado. Bogotá: Codhes.

Rúa Delgado, C. F. (2015). Los momentos de la justicia transicional en Colombia. Revista de Derecho, (N 43), 71-109.

Rúa Delgado, C. F. (2016). La justicia anamnética como construcción complementaria del paradigma de justicia transicional. Una mirada desde el caso colombiano. Revista lus et Praxis, (Año 22 N 1), 455 - 492.

Rush, P. (2014). The Arts of Transitional Justice. New York: Editorial Springer.

Russell, R., y Tokatlian, J. G. (2003). De la autonomía antagónica a la autonomía relacional: una mirada teórica desde el Cono Sur. Red de Revistas Científicas de América Latina, el Caribe, España y Portugal, (N²1), 159-194.

Solari, N. E. (2006). La niñez y sus nuevos paradigmas. Buenos Aires: Editorial La ley.

Springer, N. (2012). Como corderos entre lobos. Del uso y reclutamiento de niñas, niños y adolescentes en el marco del conflicto armado y la criminalidad en Colombia. En: Centro de memoria histórica. Recuperado de https://www.centrodememoriahistorica.gov.co/descargas/informe comoCorderosEntreLobos.pdf 
Uprimy, Rodrigo (2006): "Las enseñanzas del análisis comparado: procesos transicionales, formas de justicia transicional y el caso colombiano", en: A.A.V.V., ¿Justicia transicional sin transición? (Bogotá, Editorial de Justicia) pp. 17-44

Valencia Corominas, J. (1999). Derechos humanos del niño en el marco de la doctrina de la protección integral. Lima: Editorial Radda Barnen.

Vega, R. (2016). "Injerencia de los Estados Unidos, contrainsurgencia y terrorismo de Estado". En: E. Pizarro, Una lectura múltiple y pluralista de la historia. Recuperado de http://www.altocomisionadoparalapaz.gov.co/mesadeconversaciones/PDF/ una-lectura-multiple-y-pluralista-de-la-historia-1447178719-1460381905.pdf

Villalva Del Villar, C. A. (2012). Responsabilidad penal del adolescente dentro del conflicto armado. Revista Justicia Juris, 8 (No 1), pp. 66-74.

Watchlist on Children and Armed Conflict. (2012). Nadie en quien confiar. Los niños y el conflicto armado en Colombia. Recuperado de http://watchlist.org/wp-content/ uploads/Watchlist-ColombiaReport-Spanish-LR.pdf

Wills, M. E. (2016). "Los tres nudos de la guerra colombiana". En: E. Pizarro, Una lectura múltiple y pluralista de la historia. Recuperado de http://www.altocomisionadoparalapaz.gov.co/mesadeconversaciones/PDF/una-lectura-multiple-y-pluralista-de-la-historia-1447178719-1460381905.pdf 